\title{
Prevalence and factors associated with severe anaemia post-caesarean section at a tertiary Hospital in Southwestern Uganda
}

Sylvie Atosa Sivahikyako ${ }^{1}$, Asiphas Owaraganise ${ }^{1,2^{*}}$, Leevan Tibaijuka ${ }^{1}$, David Collins Agaba ${ }^{1}$, Musa Kayondo ${ }^{1}$, Joseph Ngonzi ${ }^{1}$, Julius Mugisha ${ }^{1}$ and Hamson Kanyesigye ${ }^{1}$

\begin{abstract}
Background: Severe anaemia after caesarean section adversely affects the woman and the new-born. While prenatal anaemia is extensively studied, the literature on post-caesarean section anaemia is limited and characteristics of women at the highest risk of developing severe anaemia after caesarean section are unknown. This study aimed to determine the prevalence and factors associated with severe anaemia on day three post caesarean section.

Methods: On the third day after caesarean section, women were consecutively enrolled in a cross-sectional study at Mbarara Regional Referral Hospital (MRRH). Women who got transfused peripartum were excluded. For every woman, we measured haemoglobin $(\mathrm{Hb})$ concentration and collected data on sociodemographic, obstetric, and medical characteristics. The primary outcome was severe anaemia after caesarean section, defined as $\mathrm{Hb}<7 \mathrm{~g} / \mathrm{dl}$. We used logistic regression analysis to determine factors associated with severe anaemia after caesarean section. $P$-value $<0.05$ was considered statistically significant.

Results: From December 2019 to March 2020, 427 of 431 screened women were enrolled in the study. Their mean age was 26.05 (SD \pm 5.84 ) years. Three hundred thirteen (73.3\%) had attended at least four antenatal care visits. The prevalence of severe anaemia post-caesarean section was 6.79\%. Foetus with macrosomia (aOR 7.9 95\%Cl: 2.18-28.85, $p<0.01$ ) and having mild or moderate anaemia pre-caesarean section (aOR:9.6, 95\%Cl: 3.91-23.77, $p<0.01$ ) were the factors associated with severe anaemia after caesarean section.

Conclusion: Severe anaemia in women post-caesarean section is relatively uncommon at our institution. It is associated with preoperative anaemia and macrosomic birth. Women with a low preoperative $\mathrm{Hb}$ concentration and those whose foetus have macrosomia could be targeted for haemoglobin optimisation before and during caesarean section.
\end{abstract}

Keywords: Severe anaemia, Day three, Post-caesarean section, Haemoglobin

*Correspondence: asiphas@gmail.com

${ }^{2}$ Infectious Diseases Research Collaboration, Kampala, Uganda

Full list of author information is available at the end of the article original author(s) and the source, provide a link to the Creative Commons licence, and indicate if changes were made. The images or other third party material in this article are included in the article's Creative Commons licence, unless indicated otherwise in a credit line to the material. If material is not included in the article's Creative Commons licence and your intended use is not permitted by statutory regulation or exceeds the permitted use, you will need to obtain permission directly from the copyright holder. To view a copy of this licence, visit http://creativecommons.org/licenses/by/4.0/. The Creative Commons Public Domain Dedication waiver (http://creativeco mmons.org/publicdomain/zero/1.0/) applies to the data made available in this article, unless otherwise stated in a credit line to the data. 


\section{Background}

Anaemia is the decrease in the total count of the red blood cells (RBCs) or packed cell volume of RBCs or haemoglobin concentration below the reference values for the person's age, sex, geographical location, and physiological status $[1,2]$, resulting into an impaired oxygen-carrying capacity of blood to the tissues. Anaemia remains a significant public health problem worldwide affecting $24.5-35.0 \%$ of women of reproductive age, especially in low-income countries (LICs) [3]. In Uganda, the prevalence of anaemia among women of childbearing age was 34\% in 2016 [4]. In the state of pregnancy, physiological haemodilution reduces haemoglobin concentration during the first trimester, reaches a nadir in the second trimester before rising again in the third trimester [5]. The haemoglobin levels continue to rise during puerperium and peak in the immediate postpartum due to diuresis-induced resolution of pregnancy-induced anaemia plus redistribution of contracting uterine circulation to the systemic circulation [6]. Recovery to nonpregnant states occurs by 12 weeks post-delivery [7]. According to the World Health Organisation (WHO), pregnancy-specific haemoglobin levels are used to categorise anaemia in pregnancy; that is, $10-10.9 \mathrm{~g} / \mathrm{dl}$ as mild anaemia, $7-9.9 \mathrm{~g} / \mathrm{dl}$ as moderate, and $<7 \mathrm{~g} / \mathrm{dl}$ as severe anaemia [8].

Maternal anaemia increases perinatal morbidity and mortality [9] including the risk of miscarriage, stillbirths, preterm birth, and low birth weight [10], the burden of depressive symptoms [11], and unfavourable mother-infant interactions [12]. Postpartum anaemia impairs wound healing, increases the risk for readmission and/or prolonged hospitalization, and increases the cost of care for families [13]. Peripartum anaemia is a crucial health issue due to increasing caesarean section rates in LICs [14].

The main risk factors for postpartum anaemia are pre-existing anaemia-especially due to iron deficiency combined with blood loss during delivery [15, 16]. Caesarean section has been shown to increase the risk of postpartum anaemia by twofold [17], due to the increased risk of uterine atony and severed vessels when opening the abdominal wall [18-20]. Incidental anaemia, especially in the third trimester, excessive intrapartum blood loss, younger women, and those not taking iron supplementation during puerperium have also been shown to predict postpartum anaemia [21].

Several studies on anaemia during pregnancy [22-24] have provided limited information on the prevalence of anaemia after delivery, especially, in women undergoing caesarean section in the context of increasing caesarean-section rates in LICs [14]. Given limited resources, most women are discharged after caesarean section with an unknown haemoglobin concentration. To skilfully identify women who are vulnerable to severe anaemia after caesarean section for appropriate intervention before hospital discharge, the prevalence of postpartum anaemia in each setting must be monitored and factors associated with anaemia after caesarean delivery evaluated. In addition, heterogeneity of peripartum population, knowledge and skills of medical personnel and logistical provision for caesarean section in different health facilities require new data on general trends of anaemia in women after delivery. This study aimed to determine the prevalence and factors associated with severe anaemia after caesarean section.

\section{Materials and methods}

\section{Study design, site, and period}

A cross-sectional study was conducted on the postnatal ward at Mbarara Regional Referral Hospital (MRRH) in Southwestern Uganda from December 2019 to March 2020. MRRH is a government-funded public tertiary hospital located along the Mbarara-Kabale road about $260 \mathrm{~km}$ south of Uganda's capital Kampala. It serves as a referral centre for the estimated $5 \mathrm{~m}$ population of southwestern Uganda [25]. The MRRH records show approximately 9000 were delivered women in 2019$40 \%$ of which were caesarean sections. The caesarean section rate is high due to a big number of pregnant women who are referred from lower-level health facilities for operative delivery. The majority end up as emergency caesarean sections due to obstructed labour, malpresentation, repeat caesarean sections, multiple pregnancies, failed labour induction, placental anomalies and non-reassuring foetus. The hospital's maternal mortality ratio stands at 261 per 100,000 live births [26]. Resident doctors in the Department of Obstetrics and Gynecology of Mbarara University of Science and Technology (MUST) conduct most of the caesarean deliveries. While Ugandan guidelines require a minimum of 24-h hospitalization postpartum [27], as a standard clinical practice at MMRH, post caesarean section, women are admitted to the postnatal ward until day three postoperative. We drew blood samples on the third day after delivery $(72 \mathrm{~h})$ to allow the minimum of $48 \mathrm{~h}$ to stabilize haemoglobin concentration following extra- and intravascular fluid volume changes during and shortly after delivery [16]. Postoperative anaemia is assessed clinically and laboratory testing offered at the discretion of the reviewing clinician.

\section{Study population}

Women who underwent caesarean section at Mbarara Regional Referral Hospital were the target population of this study. 


\section{Eligibility criteria}

We included adult women and emancipated minors at day three post-caesarean section. We excluded women who received blood transfusion peri-operatively to allow donor-recipient haemoglobin equilibration to take place [28].

\section{Sample size estimation and sampling method}

A sample size of 427 participants was estimated using the Kish Leslie formula for a single population proportion, $n=z^{2} p(1-p) / d^{2}$ [29]. We considered a 95\% confidence interval, a $5 \%$ margin of error, and a conservative $50 \%$ prevalence of severe anaemia post caesarean section (prevalence of severe anaemia after caesarean delivery is unknown in our setting). We factored a $10 \%$ non-response rate in the sample size calculation.

We used simple consecutive sampling to select the study participants.

\section{Data collection}

Under the supervision of an Obstetrician, the trained midwife research assistants collected the data using a structured questionnaire that captured study-specific variables. Daily, after the morning ward round on the postnatal ward, research staff identified women on their third post-operative day, explained the study to them and invited them to participate. Women who passed the study eligibility criteria were taken through an informed consenting process before enrolment into the study.

\section{Laboratory procedures}

To estimate haemoglobin concentration, about $5 \mathrm{mls}$ of blood from a superficial vein on the forearm was drawn into an EDTA vacutainer and taken to MRRH's laboratory. The laboratory technologist measured the haemoglobin level using an automated meter (Sysmex $\mathrm{XN}-1000 \mathrm{i}^{\circledR}$ 5-part haematology analyser, Sysmex America, Inc. Lincolnshire, Illinois, USA) as described by Wang and colleagues [30]. For quality control, the analyser was cleaned and manufacturer-supplied controls run before testing samples. Using a closed mode of blood sampling, the analyser automatically sampled, processed, analysed blood and printed out haemoglobin level.

\section{Study variables}

The outcome variable was severe anaemia defined as haemoglobin $<7.0 \mathrm{~g} / \mathrm{dl}[10]$. The independent variables were the woman's demographic characteristics-age, marital status, occupation, residence, and level of education; medical characteristics-predelivery haemoglobin concentration (abstracted from woman's chart), HIV serostatus, and history of malaria in the current pregnancy, diabetes; and obstetric characteristics-parity, gestational age, prenatal care attendance, iron supplement and duration, history of previous caesarean section, inter-delivery interval, history of pre-eclampsia, multifetal gestation. Other variables abstracted from the patient's chart were: the type of caesarean section (emergency versus elective), indication for the caesarean section, birth weight (fetal macrosomia was defined as neonatal birthweight $\geq 4000 \mathrm{~g}$ [31]), and surgeon's estimated blood loss.

For quality assurance, the questionnaire was pretested on pregnant women seeking antenatal care at the maternity ward of MRRH and the inconsistencies identified were corrected. The completed questionnaires were checked for completeness daily on-site and missing fields filled.

\section{Data entry and analysis}

Completed questionnaires were entered into an EPI-Info (www.epidata.dk version 7.2.1) database and imported into STATA (StataCorp, College Station, Texas, U.S.A) version $\mathbf{1 5 . 0}$ for analysis. We described maternal baseline characteristics using means and standard deviation for continuous variables and proportions for categorical variables.

To determine the prevalence of severe anaemia postcaesarean section, haemoglobin concentration was categorized as severe anaemia $(<7 \mathrm{~g} / \mathrm{dl})$ and no severe anaemia $(\geq 7 \mathrm{~g} / \mathrm{dl})$. We then calculated the proportion of women enrolled in the study who underwent caesarean section with haemoglobin concentration $<7 \mathrm{~g} / \mathrm{dl}$. To determine factors associated with severe anaemia, variables with $p$-value $<0.2$ at bivariate logistic regression were entered into a multiple logistic regression model to determine factors independently associated with severe anaemia. A $p$-value less than 0.05 was considered statistically significant.

\section{Ethical consideration}

Ethical approval was obtained from the Mbarara University Research Ethics Committee (MUST REC); Protocol reference number: 21/10-19. Written informed consent was obtained from all study participants. Adults aged $\geq 18$ years and those aged $<18$ years independently consented as emancipated minors in line with Ugandan guidelines [32]. The health workers in the postnatal ward were immediately informed about any woman who needed further evaluation and management of anaemia.

\section{Results}

A total of 431 women were screened on day three postcaesarean section. We enrolled 427 participants and excluded 4 who received a blood transfusion in the immediate peripartum period. The mean age of the 
Table 1 Baseline characteristics of women with/out severe anaemia after caesarean section at MRRH $(N=427)$

\begin{tabular}{|c|c|c|c|c|}
\hline \multirow[t]{3}{*}{ Characteristics } & \multirow{3}{*}{$\begin{array}{l}\text { Overall }(\mathrm{N}=427) \\
\mathrm{n} / \mathrm{N}(\%)\end{array}$} & \multicolumn{2}{|c|}{ Severe Anaemia } & \multirow[t]{3}{*}{$P$-value } \\
\hline & & Yes $(N=29)$ & No $(N=398)$ & \\
\hline & & $\mathrm{n} / \mathrm{N}(\%)$ & $\mathrm{n} / \mathrm{N}(\%)$ & \\
\hline Age in years, mean $( \pm S D)$ & $26.05( \pm 5.84)$ & $26.0( \pm 7.52)$ & $26.06 \pm 5.70$ & 0.955 \\
\hline \multicolumn{2}{|l|}{ Age category, n (\%) } & & & 0.007 \\
\hline $15-24$ & 194(45.4) & $16(55.2)$ & $178(44.7)$ & \\
\hline $25-34$ & $188(44.0)$ & $6(20.7)$ & $182(45.7)$ & \\
\hline $35+$ & $45(10.5)$ & $7(24.1)$ & $38(9.6)$ & \\
\hline \multicolumn{2}{|l|}{ Residence, n (\%) } & & & 0.993 \\
\hline Rural & $250(58.5)$ & 17(58.6) & 233(58.5) & \\
\hline Urban & $177(41.5)$ & $12(41.4)$ & $165(41.5)$ & \\
\hline \multicolumn{2}{|l|}{ Marital status, n (\%) } & & & 0.321 \\
\hline Single & $26(6.1)$ & $3(10.3)$ & $23(5.8)$ & \\
\hline Married & $401(93.9)$ & 26(89.7) & $375(94.2)$ & \\
\hline \multicolumn{2}{|l|}{ Occupation, n (\%) } & & & 0.634 \\
\hline Employed & $104(24.4)$ & $6(20.7)$ & $98(24.6)$ & \\
\hline Unemployed & $323(75.6)$ & 23(79.3) & $300(75.4)$ & \\
\hline \multicolumn{2}{|l|}{ Education, n (\%) } & & & 0.164 \\
\hline No formal & $43(10.1)$ & $4(13.8)$ & $39(9.8)$ & \\
\hline Primary & 198(46.4) & 16(55.2) & $182(45.7)$ & \\
\hline$\geq$ Secondary & 186(43.6) & $9(31.0)$ & $177(44.5)$ & \\
\hline \multicolumn{2}{|l|}{ ANC visits, n (\%) } & & & 0.233 \\
\hline$<4$ & $114(26.7)$ & $5(17.2)$ & $109(27.4)$ & \\
\hline$\geq 4$ & $313(73.3)$ & $24(82.8)$ & 289(72.6) & \\
\hline \multicolumn{2}{|l|}{ Parity, n (\%) } & & & 0.261 \\
\hline Primiparous & 190(44.5) & $10(34.5)$ & $180(45.2)$ & \\
\hline Multiparous & $237(55.5)$ & 19(65.5) & 218(54.8) & \\
\hline \multicolumn{2}{|l|}{ Pre-caesarean Hb (g/dL), n (\%) } & & & $<0.001^{*}$ \\
\hline$\geq 11$ & $365(85.5)$ & 14(48.3) & $351(88.2)$ & \\
\hline $7.0-10.9$ & $62(14.5)$ & 15(51.7) & $47(11.8)$ & \\
\hline \multicolumn{2}{|l|}{ Prior caesarean sections, n (\%) } & & & $0.001^{*}$ \\
\hline Index & $228(53.4)$ & 25(86.2) & 203(51.0) & \\
\hline Once & $90(21.1)$ & $1(3.5)$ & $89(22.4)$ & \\
\hline$\geq 2$ & $109(25.5)$ & $3(10.3)$ & 106(26.6) & \\
\hline \multicolumn{2}{|l|}{ HIV status, n (\%) } & & & 0.469 \\
\hline Negative & 397(93.0) & 26(89.7) & $371(93.2)$ & \\
\hline Positive & $30(7.0)$ & $3(10.3)$ & $27(6.8)$ & \\
\hline \multicolumn{2}{|l|}{ Caesarean section type, $\mathrm{n}(\%)$} & & & 0.053 \\
\hline Emergency & $381(89.2)$ & $29(100.0)$ & $352(88.4)$ & \\
\hline Elective & $46(10.8)$ & $0(0.0)$ & $46(11.6)$ & \\
\hline \multicolumn{2}{|l|}{ Delivered macrosomic foetus (\%) } & & & $<0.001^{*}$ \\
\hline No & $401(93.9)$ & $22(75.9)$ & $379(95.2)$ & \\
\hline Yes & $26(6.1)$ & $7(24.1)$ & 19(4.8) & \\
\hline \multicolumn{2}{|l|}{ Prior scar, n (\%) } & & & $0.008^{*}$ \\
\hline No & $287(67.2)$ & 26(89.7) & $261(65.6)$ & \\
\hline Yes & $140(32.8)$ & $3(10.3)$ & 137(34.4) & \\
\hline \multicolumn{2}{|l|}{ Prolonged labour, n (\%) } & & & $0.024^{*}$ \\
\hline No & $324(75.9)$ & 17(58.6) & $307(77.1)$ & \\
\hline Yes & 103(24.1) & 12(41.4) & $91(22.9)$ & \\
\hline \multicolumn{2}{|l|}{ Multiple pregnancy, n (\%) } & & & 0.333 \\
\hline
\end{tabular}


Table 1 (continued)

\begin{tabular}{|c|c|c|c|c|}
\hline \multirow[t]{3}{*}{ Characteristics } & \multirow{3}{*}{$\begin{array}{l}\text { Overall }(\mathrm{N}=427) \\
\mathrm{n} / \mathrm{N}(\%)\end{array}$} & \multicolumn{2}{|c|}{ Severe Anaemia } & \multirow[t]{3}{*}{$P$-value } \\
\hline & & Yes $(N=29)$ & No $(N=398)$ & \\
\hline & & $\mathrm{n} / \mathrm{N}(\%)$ & $\mathrm{n} / \mathrm{N}(\%)$ & \\
\hline No & $421(98.6)$ & 28(96.6) & 393(98.7) & \\
\hline Yes & $6(1.4)$ & $1(3.5)$ & $5(1.3)$ & \\
\hline Malpresentation, n (\%) & & & & 0.198 \\
\hline No & $382(89.5)$ & 28(96.6) & $354(88.9)$ & \\
\hline Yes & $45(10.5)$ & $1(3.5)$ & $44(11.1)$ & \\
\hline Severe preeclampsia, n (\%) & & & & 0.067 \\
\hline No & $424(99.3)$ & 28(96.6) & 396(99.5) & \\
\hline Yes & $3(0.7)$ & $1(3.5)$ & $2(0.5)$ & \\
\hline
\end{tabular}

M Mean, SD Standard deviation

enrolled participants was 26.1 ( \pm 5.84$)$ years). Ninety four percent $(n=401)$ were married, $73.3 \%(n=313)$ attended at least four prenatal visits and $43.6 \%(n=186)$ attained at least secondary level education. Other participants baseline characteristics are shown in Table 1.

Of the 247 enrolled participants, 29 had haemoglobin level $<7 \mathrm{~g} / \mathrm{dl}$, giving a prevalence of severe anaemia of 6.79 (95\%CI: 4.78-9.61) per cent.

The factors independently associated with severe anaemia post caesarean section as presented in Table 2 were: having mild or moderate anaemia pre-caesarean section (aOR 9.6, 95\%CI: 3.91-23.77, $p<0.01$ ), and a macrosomic birth>400g (aOR: 7.9, 95\% CI:2.18-28.85, $p<0.01$ ).

\section{Discussion}

Our study showed that the prevalence of severe anaemia on the third-day post caesarean section at Mbarara Regional Referral Hospital was 6.79\%. Given that most of the studies on anaemia are conducted during pregnancy, our study provides insights into the prevalence of severe anaemia after caesarean delivery in LICs' settings where caesarean section rates are raising. In this study, the prevalence of severe anaemia after the caesarean section was higher than what was reported in Northern Uganda (0.8\%), mid-western Uganda (0.5\%) [33], as well as in postpartum women in North East Ethiopia (0.7\%) [34] and India (2\%) [35]. Also, our found prevalence is higher than reported one in 30 women in German who had severe anaemia (cut-off haemoglobin level $<8 \mathrm{~g} / \mathrm{dl}$ ) on the second day after delivery [17]. Moreover, a literature review found the prevalence of postpartum anaemia to range between 50 and $80 \%$ in developing countries [16]. The variations in prevalence of postpartum anaemia are due to disagreements among international clinical practice guidelines on cut-off diagnostic haemoglobin levels, the timing to test haemoglobin concentration, heterogeneity in populations of women at the individual level, plus the organisational setting-specific factors [8, 36]. Although an insignificant change in haemoglobin concentration among women who underwent noncomplicated caesarean section has been reported [37], it is important to determine haemoglobin level before hospital discharge in women after caesarean delivery.

In this study, mild or moderate anaemia pre-caesarean section and a macrosomic birth $>4000 \mathrm{~g}$ remained independently associated with severe anaemia post caesarean section at MRRH. Women with mild or moderate anaemia pre-caesarean section had up to ten times higher odds of suffering severe anaemia post-caesarean section-in agreement with other studies conducted at tertiary hospitals in sub-Saharan Africa [15, 38-40]. Similar findings were reported by a study conducted in Southwest Nigeria that showed up to twelve times higher odds of receiving blood transfusion among women with pre-caesarean anaemia [38]; and another observational study that found four times higher odds of suffering postoperative anaemia [39]. Also, a study in Egypt found haemoglobin below $11.0 \mathrm{~g} / \mathrm{dL}$ to be a risk factor for primary postpartum haemorrhage up to seven times and subsequent severe anaemia postpartum regardless of the mode of delivery [40]. Low predelivery haemoglobin impairs transport of oxygen to the uterus, causes cellular dysfunction, a mechanism that can be used to explain impaired myometrial contractility, uterine atony and postpartum haemorrhage that aggravates pre-existing anaemia. Also, the preoperative anaemia that was present in the first place was aggravated by the blood loss during the caesarean section leading to post-operative anaemia.

In addition, this study found that pregnant women who had a macrosomic birth were eight times likely to develop severe anaemia after caesarean section. This was consistent with previous studies reporting an increased 
Table 2 Crude and adjusted odds ratios of factors associated with severe anaemia after caesarean section at MRRH ( $\mathrm{N}=427)$

\begin{tabular}{|c|c|c|c|c|c|c|}
\hline \multirow[t]{2}{*}{ Factor } & \multicolumn{2}{|c|}{ Severe Anaemia } & \multirow[t]{2}{*}{$\operatorname{cOR}(95 \% \mathrm{Cl})$} & \multirow[t]{2}{*}{ P-value } & \multirow[t]{2}{*}{ aOR(95\%Cl) } & \multirow[t]{2}{*}{ P-value } \\
\hline & Yes & No & & & & \\
\hline \multicolumn{7}{|l|}{ Age (years) } \\
\hline $15-24$ & $16(55.2)$ & 178(44.7) & Reference & & & \\
\hline $25-34$ & $6(20.7)$ & $182(45.7)$ & $0.4(0.14-0.96)$ & 0.041 & $0.6(0.19-1.70)$ & 0.312 \\
\hline $35+$ & $7(24.1)$ & $38(9.6)$ & $2.0(0.79-5.32)$ & 0.141 & $1.9(0.95-9.50)$ & 0.149 \\
\hline \multicolumn{7}{|c|}{ Pre-caesarean section haemoglobin (g/dL) } \\
\hline$\geq 11.0$ & 13(44.8) & $352(88.4)$ & Reference & & & \\
\hline $7.0-10.9$ & 16(55.1) & $46(11.6)$ & $9.4(4.26-20.81)$ & $<0.01$ & $9.6(3.91-23.76)$ & $<0.01$ \\
\hline \multicolumn{7}{|c|}{ Delivery of macrosomia foetus } \\
\hline No & $22(75.9)$ & $379(95.2)$ & Reference & & & \\
\hline Yes & $7(24.1)$ & $19(4.8)$ & $6.3(2.41-17.70)$ & 0.001 & $7.9(2.18-28.85)$ & 0.002 \\
\hline \multicolumn{7}{|c|}{ Number of prior caesarean section } \\
\hline None & 24(82.8) & 204(51.3) & Reference & & & \\
\hline One & $2(6.9)$ & $89(22.3)$ & $0.2(0.04-0.82)$ & 0.026 & $0.3(0.06-1.67)$ & 0.174 \\
\hline$\geq 2$ & $3(10.3)$ & 105(26.4) & $0.2(0.07-0.82)$ & 0.023 & $0.7(0.14-3.57)$ & 0.666 \\
\hline \multicolumn{7}{|c|}{ Indication for the current caesarean section } \\
\hline \multicolumn{7}{|l|}{ Prior scar } \\
\hline No & 26(89.7) & $258(64.8)$ & Reference & & & \\
\hline Yes & $3(10.3)$ & $140(35.2)$ & $0.2(0.06-0.72)$ & 0.012 & $0.7(0.10-5.85)$ & 0.174 \\
\hline \multicolumn{7}{|c|}{ Prolonged labour } \\
\hline No & $16(55.2)$ & $308(77.4)$ & Reference & & & \\
\hline Yes & $13(44.8)$ & $90(22.6)$ & $2.8(1.29-6.00)$ & 0.009 & $5.0(0.93-27.27)$ & 0.060 \\
\hline \multicolumn{7}{|c|}{ Antenatal care visits } \\
\hline$<4$ & $5(17.2)$ & $109(27.4)$ & Reference & & & \\
\hline$\geq 4$ & 24(82.8) & $289(72.6)$ & $1.8(0.7-4.9)$ & 0.239 & & \\
\hline \multicolumn{7}{|l|}{ Parity } \\
\hline Primiparous & $10(34.5)$ & $180(45.2)$ & Reference & & & \\
\hline Multiparous & $19(65.5)$ & $218(54.8)$ & $1.6(0.7-3.5)$ & 0.264 & & \\
\hline \multicolumn{7}{|l|}{ Preeclampsia } \\
\hline No & 28(96.6) & 396(99.5) & Reference & & & \\
\hline Yes & $1(3.5)$ & $2(0.5)$ & $7.1(0.6-80.4)$ & 0.255 & & \\
\hline \multicolumn{7}{|l|}{ Malpresentation } \\
\hline No & 28(96.6) & $354(88.9)$ & Reference & & & \\
\hline Yes & $1(3.5)$ & $44(11.1)$ & $0.3(0.04-2.2)$ & 0.226 & & \\
\hline \multicolumn{7}{|c|}{ Multiple pregnancy } \\
\hline No & 28(96.6) & 393(98.7) & Reference & & & \\
\hline Yes & $1(3.5)$ & $5(1.3)$ & $2.8(0.3-24.9)$ & 0.354 & & \\
\hline \multicolumn{7}{|l|}{ HIV } \\
\hline Negative & 26(89.7) & $371(93.2)$ & Reference & & & \\
\hline Positive & $3(10.3)$ & $27(6.8)$ & $1.6(0.5-5.6)$ & 0.472 & & \\
\hline
\end{tabular}

OR Odds Ratio, aOR Adjusted odds ratio, Cl Confidence Interval, ${ }^{*} p<0.05$

risk of postpartum haemorrhage and subsequent postpartum anaemia in women with macrosomia foetuses [40-42] including a study from Uganda. In the Ugandan study, the risk for postpartum haemorrhage was found to double after delivery of large babies over $4000 \mathrm{~g}$, regardless of the mode of delivery [43], while in Egypt, a woman with macrosomia foetus was ten times likely to develop postpartum anaemia [42]. Foetal macrosomia leads to prolonged labour and other maternal complications, including operative delivery and postpartum haemorrhage, leading to subsequent severe anaemia. The increased physiologic vascularity of the pregnant 
uterus plus severed vessels during surgical access to the abdominal cavity confers a higher risk of postpartum haemorrhage and subsequent severe anaemia to women undergoing caesarean section.

Our study demonstrates that to diagnose severe anaemia earlier and institute proper treatment, women with a low preoperative $\mathrm{Hb}$ concentration and those whose foetus have macrosomia could be targeted for screening and haemoglobin optimisation before and during caesarean section.

Our study was not without limitations. We could not assess the association with estimated blood loss because surgeon-estimated blood loss was recorded in less than half of all participants. But, tendentially, the severe course of anaemia in these women was consistent with previous literature indicating a higher incidence of postpartum anaemia in women with excessive recorded or perceived intrapartum blood loss. Also, we excluded women who received blood transfusion which could have underestimated the prevalence of severe anaemia in this study. However, this was a small number and did not significantly alter our findings. Similarly, most studies on this subject matter rely on different thresholds of haemoglobin levels to classify anaemia. This makes it challenging to compare across studies. The findings of this study are only generalizable to women that undergo a caesarean section. Nonetheless, we demonstrate the prevalence of severe anaemia after caesarean section and provide insights into women at the highest risk for postoperative anaemia.

\section{Conclusion}

In summary, we found that severe anaemia after caesarean section is uncommon in women undergoing cesarean section at our institution. It is associated with anaemia before surgery and delivery of a macrosomic foetus. In women delivered by caesarean section, we recommend haemoglobin determination before hospital discharge to diagnose and treat anaemia promptly.

\section{Abbreviations}

EDTA : Ethylenediamine tetra acetic acid; Hb: Haemoglobin; MRRH: Mbarara Regional Referral Hospital; MUST: Mbarara University of Science and Technology; REC: Research Ethics Committee; RBC: Red blood cells; UNCST: Uganda National Council for Science and Technology.

\section{Supplementary Information}

The online version contains supplementary material available at https://doi. org/10.1186/s12884-021-04157-x.

Additional file 1.

\section{Acknowledgements}

We acknowledge the administrative support from the Mbarara Regional Referral Hospital, Mbarara, Uganda where this study was conducted. We thank Sr Josephine Mulere who facilitated data collection as well as our study participants who took part in the study.

\section{Authors' contributions}

SSA conceived the original study design. SSA and OA wrote the first draft of the manuscript. MK, LT, JN, and AC conducted the analysis. JM and HM oversaw study conduct and data collection. All authors were involved in data interpretation, reviewed the manuscript, and provided critical edits. All authors read and approved the final version of the article to be submitted for publication, and agree to be accountable for the article and to ensure that all questions regarding the accuracy or integrity of the article are investigated and resolved.

\section{Authors' information}

Not applicable.

\section{Funding}

Not applicable.

\section{Availability of data and materials}

De-identified data sufficient to produce primary study findings will be made available on reasonable request to the Department of Obstetrics and Gynecology, Mbarara University of Science and Technology. Data requests can be submitted through the corresponding author.

\section{Declarations}

Ethics approval and consent to participate

We obtained ethical approval for this study from the Institutional Review Board: Mbarara University of Science and Technology Research Ethics Committee (MUST REC); Protocol reference number: 21/10-19. All women consented before study participation. All study methods were performed in accordance with the Declaration of Helsinki guidelines and regulations.

\section{Consent for publication}

Written informed consent for publication was obtained from the participants. Copies of the written consent are available for review by the Editor of this journal.

\section{Competing interests}

We declare no competing interests.

\section{Author details}

${ }^{1}$ Department of Obstetrics and Gynaecology, Mbarara University of Science and Technology, P.O. Box 1410, Mbarara, Uganda. ${ }^{2}$ Infectious Diseases Research Collaboration, Kampala, Uganda.

Received: 24 January 2021 Accepted: 27 September 2021 Published online: 06 October 2021

\section{References}

1. Turgeon ML. Clinical hematology: theory and procedures. 5th ed. Philadelpia: Lippincott Williams and Wilkins; 2012. p. 307-41.

2. Rodak BF, Fritsma GA, Keohane E. Hematology-E-book: clinical principles and applications: Elsevier health sciences; 2013. StatPearls [Internet]

3. WHO. The global prevalence of anaemia in 2011. Geneva: World Health Organization; 2015

4. Uganda Bureau of Statistics - UBOS, ICF. Uganda demographic and health survey 2016. Kampala: UBOS and ICF; 2018.

5. DeMaeyer EM, Dallman P, Gurney JM, Hallberg L, Sood S, Srikantia S, et al. Preventing and controlling iron deficiency anaemia through primary health care: a guide for health administrators and programme managers: World Health Organization; 1989.

6. Akinlaja O. Hematological changes in pregnancy-the preparation for intrapartum blood loss. Obstet Gynecol Int J. 2016;4(3):00109. 
7. Chauhan G, Tadi P. Physiology, postpartum changes; 2020.

8. WHO. Haemoglobin concentrations for the diagnosis of anaemia and assessment of severity: World Health Organization; 2011.

9. Christian P. Nutrition and maternal survival in developing countries. In: Handbook of nutrition and pregnancy: Springer; 2008. p. 319-36.

10. WHO. Global nutrition targets 2025: stunting policy brief: World Health Organization; 2014.

11. Corwin EJ, Murray-Kolb LE, Beard JL. Low hemoglobin level is a risk factor for postpartum depression. J Nutr. 2003;133(12):4139-42.

12. Perez EM, Hendricks MK, Beard JL, Murray-Kolb LE, Berg A, Tomlinson M, et al. Mother-infant interactions and infant development are altered by maternal iron deficiency anemia. J Nutr. 2005;135(4):850-5.

13. Breymann C, Honegger C, Holzgreve W, Surbek D. Diagnosis and treatment of iron-deficiency anaemia during pregnancy and postpartum. Arch Gynecol Obstet. 2010;282(5):577-80.

14. Atuheire EB, Opio DN, Kadobera D, Ario AR, Matovu JK, Harris J, et al, Spatial and temporal trends of cesarean deliveries in Uganda: 2012-2016. BMC Pregnancy Childbirth. 2019;19(1):132.

15. Butwick AJ, Walsh EM, Kuzniewicz M, Li SX, Escobar GJ. Patterns and predictors of severe postpartum anemia after $\mathrm{C}$ esarean section. Transfusion. 2017;57(1):36-44.

16. Milman N. Postpartum anemia I: definition, prevalence, causes, and consequences. Ann Hematol. 2011;90(11):1247-53.

17. Bergmann RL, Richter R, Bergmann KE, Dudenhausen JW. Prevalence and risk factors for early postpartum anemia. Eur J Obstet Gynecol Reprod Biol. 2010;150(2):126-31.

18. Joseph K, Rouleau J, Kramer M, Young D, Liston R, Baskett T. System MHSGotCPS: investigation of an increase in postpartum haemorrhage in Canada. BJOG Int J Obstet Gynaecol. 2007;1 14(6):751-9.

19. Carroli G, Cuesta C, Abalos E, Gulmezoglu AM. Epidemiology of postpartum haemorrhage: a systematic review. Best Pract Res Clin Obstetr Gynaecol. 2008;22(6):999-1012.

20. Kramer MS, Berg C, Abenhaim H, Dahhou M, Rouleau J, Mehrabadi A, et al. Incidence, risk factors, and temporal trends in severe postpartum hemorrhage. Am J Obstet Gynecol. 2013;209(5):449 e441-449. e447.

21. Bodnar LM, Siega-Riz AM, Miller WC, Cogswell ME, McDonald T. Who should be screened for postpartum anemia? An evaluation of current recommendations. Am J Epidemiol. 2002;156(10):903-12.

22. McLean E, Cogswell M, Egli I, Wojdyla D, De Benoist B. Worldwide prevalence of anaemia, $\mathrm{WHO}$ vitamin and mineral nutrition information system, 1993-2005. Public Health Nutr. 2009;12(4):444-54.

23. Obstetricians ACo, Gynecologists. ACOG practice bulletin no. 95: anemia in pregnancy. Obstet Gynecol. 2008;112(1):201.

24. Okia CC, Aine B, Kiiza R, Omuba P, Wagubi R, Muwanguzi E, et al. Prevalence, morphological classification, and factors associated with anemia among pregnant women accessing antenatal clinic at Itojo hospital, South Western Uganda. J Blood Med. 2019;10:351.

25. UBOS. The national population and housing census 2014-main report. Kampala: Uganda Bureau of Statistics; 2016.

26. Lugobe HM, Muhindo R, Kayondo M, Wilkinson I, Agaba DC, McEniery C, et al. Risks of adverse perinatal and maternal outcomes among women with hypertensive disorders of pregnancy in southwestern Uganda. PLoS One. 2020;15(10):e0241207.
27. MOH. Essential maternal and newborn clinical care guidelines for Uganda. Kampala: Division RH; 2016.

28. Wiesen AR, Hospenthal DR, Byrd JC, Glass KL, Howard RS, DiehI LF. Equilibration of hemoglobin concentration after transfusion in medical inpatients not actively bleeding. Ann Intern Med. 1994;121(4):278-80.

29. Kish L, Kish L. Survey sampling. Biometrische Zeitschrift 1965. 1965;10(1):88-9 John Wiley \& Sons, Inc., New York, London. IX+ 643 S., 31 Abb., 56 Tab., Preis $83 \mathrm{~s}$.

30. Wang J, Zhao S, Su Z, Liu X. Analytical comparison between two hematological analyzer systems: Mindray BC-5180 vs Sysmex XN-1000. J Clin Lab Anal. 2019;33(8):e22955.

31. Boulet SL, Alexander GR, Salihu HM, Pass M. Macrosomic births in the United States: determinants, outcomes, and proposed grades of risk. Am J Obstet Gynecol. 2003;188(5):1372-8.

32. UNCST. National guidelines for research involving humans as research participants: Uganda National Council for Scince and technology Kampala-Uganda; 2014

33. Obai G, Odongo P, Wanyama R. Prevalence of anaemia and associated risk factors among pregnant women attending antenatal care in Gulu and Hoima regional hospitals in Uganda: a cross sectional study. BMC Pregnancy Childbirth. 2016;16:76.

34. Abebaw A, Gudayu TW, Kelkay B. Proportion of immediate postpartum Anaemia and associated factors among postnatal mothers in Northwest Ethiopia: a cross-sectional study. Anemia. 2020;2020:8979740.

35. Somdatta P, Reddaiah V, Singh B. Prevalence of anaemia in the postpartum period: a study of a north Indian village. Trop Dr. 2009;39(4):211-5.

36. Milman N, Bergholt T, Byg KE, Eriksen L, Hvas AM. Reference intervals for haematological variables during normal pregnancy and postpartum in 434 healthy Danish women. Eur J Haematol. 2007;79(1):39-46.

37. Abdelazim I, Farghali M, Amer OO. Routine haemoglobin assay after uncomplicated caesarean sections. Przeglad menopauzalny = Menopause Rev. 2021;20(1):29-33.

38. Akinlusi FM, Rabiu KA, Durojaiye IA, Adewunmi AA, Ottun TA, Oshodi YA. Caesarean delivery-related blood transfusion: correlates in a tertiary hospital in Southwest Nigeria. BMC Pregnancy Childbirth. 2018;18(1):24.

39. Anzaku AS, Edem BE, Ngwan SD, Galadima SJ. Do patients require routine hematocrit testing following uncomplicated cesarean delivery? Afr J Med Health Sci. 2015;14(1):24.

40. El Badawy A, Waly E, Zaitoun N, Abo-Elwan Y. Assessment of risk factors for primary postpartum hemorrhage at Zagazig university hospitals. Zagazig Univ Med J. 2017;23(2):1-9.

41. Cheng YK-Y, Lao TT. Fetal and maternal complications in macrosomic pregnancies. Res Rep Neonatol. 2014;4:65.

42. Madoue GB, Sile SN, Lhagadang F. Foetal macrosomia: risk factors, maternal and foetal outcomes in N'Djamena mother and child hospital. Chad South Sudan Med J. 2018;11(2):40-3.

43. Ononge, et al. Incidence and risk factors for postpartum hemorrhage in Uganda. Reprod Health. 2016;13(1):1-7.

\section{Publisher's Note}

Springer Nature remains neutral with regard to jurisdictional claims in published maps and institutional affiliations.

Ready to submit your research? Choose BMC and benefit from

- fast, convenient online submission

- thorough peer review by experienced researchers in your field

- rapid publication on acceptance

- support for research data, including large and complex data types

- gold Open Access which fosters wider collaboration and increased citations

- maximum visibility for your research: over $100 \mathrm{M}$ website views per year

At BMC, research is always in progress.

Learn more biomedcentral.com/submissions 